\title{
Economic evaluation of an exercise- counselling intervention to enhance smoking cessation outcomes: The Fit2Quit trial
}

William Leung ${ }^{1,2^{*}}$, Vaughan Roberts ${ }^{2}$, Louisa G. Gordon ${ }^{3}$, Christopher Bullen², Hayden McRobbie ${ }^{4}$, Harry Prapavessis ${ }^{5}$, Yannan Jiang ${ }^{2}$ and Ralph Maddison ${ }^{2,6}$

\begin{abstract}
Background: In the Fit2Quit randomised controlled trial, insufficiently-active adult cigarette smokers who contacted Quitline for support to quit smoking were randomised to usual Quitline support or to also receive $\leq 10$ face-to-face and telephone exercise-support sessions delivered by trained exercise facilitators over the 24-week trial. This paper aims to determine the cost-effectiveness of an exercise-counselling intervention added to Quitline compared to Quitline alone in the Fit2Quit trial.

Methods: Within-trial and lifetime cost-effectiveness were assessed. A published Markov model was adapted, with smokers facing increased risks of lung cancer and cardiovascular disease.

Results: Over 24 weeks, the incremental programme cost per participant in the intervention was NZ\$428 (US\$289 or $€ 226$; purchasing power parity-adjusted [PPP]). The incremental cost-effectiveness ratio (ICER) for seven-day point prevalence measured at 24-week follow-up was NZ\$31,733 (US\$21,432 or €16,737 PPP-adjusted) per smoker abstaining. However, for the $52 \%$ who adhered to the intervention ( $\geq 7$ contacts), the ICER for point prevalence was $\mathrm{NZ} \$ 3,991$ (US\$2,695 or €2,105 PPP-adjusted). In this adherent subgroup, the Markov model estimated 0.057 and 0.068 discounted quality-adjusted life-year gains over the lifetime of 40-year-old males (ICER: NZ\$4,431; US\$2,993 or €2,337 PPP-adjusted) and females (ICER: NZ\$2,909; US\$1,965 or €1,534 PPP-adjusted).
\end{abstract}

Conclusions: The exercise-counselling intervention will only be cost-effective if adherence is a minimum of $\geq 7$ intervention calls, which in turn leads to a sufficient number of quitters for health gains.

Trial registration: Australasian Clinical Trials Registry Number ACTRN12609000637246

Keywords: Economic evaluation, Exercise, Smoking cessation, Randomised controlled trial

\section{Background}

Smoking cessation is an important public health challenge as it has intermediate and long-term health benefits. Treatments to aid smoking cessation that are widely available, accessible, and cost-effective would therefore have great potential for public health benefit.

\footnotetext{
* Correspondence: william.leung@otago.ac.nz

${ }^{1}$ University of Otago, WellingtonPO Box 7343New Zealand

${ }^{2}$ University of Auckland, Private Bag 92019, Auckland, New Zealand

Full list of author information is available at the end of the article
}

Despite the availability of effective treatments for smoking cessation in many countries, the proportion of people who successfully quit smoking is disappointingly low $[1,2]$. New approaches to sustain the implementation of effective smoking cessation treatments are needed. One option proposed as an aid for smoking cessation is the use of exercise.

A recent Cochrane review of exercise interventions for smoking cessation identified 20 randomised controlled trials $(n=5870)$ with adequate follow-up (ie, at least six months after the quit date) [3]. However, only 2 of the 
20 trials offered evidence that exercise aided smoking cessation in the long term.

The authors of the Cochrane review highlighted a number of methodological issues that have limited previous research: small sample sizes, lack of statistical power, gender bias, lack of sufficient intensity or duration of the intervention to positively affect smoking outcomes, and reliance on structured supervised exercise regimens, which limits scalability. Moreover, there is a complete dearth of research to evaluate the cost-effectiveness of this approach. The Fit2Quit trial was conducted in an attempt to address some of these methodological concerns that were identified in an earlier version of the Cochrane review, and to determine the cost-effectiveness of an exercise-counselling intervention in addition to standard smoking cessation support to enhance abstinence rates compared to standard cessation support alone. The objective of this paper is to present the within-trial (at 24-week follow-up) and lifetime cost-effectiveness analysis (using a Markov model) of the Fit2Quit trial. Additionally, we sought to identify how cost-effectiveness would alter by investigating a subgroup of intervention participants who adhered well to the intervention, that is, those who may incur greater intervention costs but potentially have greater quit rates. This may be of use in directing future research and future counselling program improvement.

\section{Methods}

\section{Trial and intervention summary}

The full details of the design and conduct of the Fit2Quit trial have been published elsewhere [4]. In brief, it was a parallel group two-arm randomised controlled trial conducted in New Zealand (NZ) between 2009 and 2012. Participants were randomised at a 1:1 ratio to either receive an exercise intervention plus usual stop smoking support, or to usual stop smoking support alone (ie, Quitline). Table 1 shows the baseline characteristics of the trial participants $(n=906)$. There were no significant differences in socio-demographic, smoking and physical activity profiles at baseline between control and intervention groups. All enrolled participants were encouraged to set a quit date, and offered one-to-one Quitline telephone support for three months, as well as up to eight weeks of subsidised nicotine replacement therapy.

Intervention group participants $(n=455)$ commenced a six-month home and community-based exercise programme delivered by Green Prescription (GRx) services, delivered in 10 contacts (face-to-face and telephone support sessions) over six months. GRx involves a referral from primary care to agencies that support physical activity [5]. In this trial however, participants randomised to the intervention group were referred by the researcher, without involving a General Practitioner. Once referred, trained exercise-facilitators (participant-support person [PSPs]) contacted participants and offered telephone counselling to promote and support exercise behavior. PSPs encouraged participants to work towards a goal of partaking in $\geq 30 \mathrm{~min}$ of moderatevigorous aerobic-based exercise on most days of the week, in line with the 1996 US Surgeon General's recommendations [6].

The Fit2Quit trial results have been reported elsewhere [7]. Smoking abstinence rates at 24 weeks were moderately high, but not statistically significantly different between intervention and control groups. Of the 455 participants who were randomised to the intervention group, $52 \%(n=236)$ completed at least seven of the ten intervention calls (median number of calls $=7$, interquartile range $=4-9$ ), hereafter the adherent intervention group. When compared with the control group, a significant treatment effect on smoking cessation was found for those who were in the adherent intervention group (OR 0.67, $95 \%$ CI 0.46 to $0.98, p=0.04$ ). Therefore, the economic evaluation using a lifetime horizon is focused on this adherent intervention group.

\section{Outcomes data}

Follow-up assessments were completed at 8 and 24 weeks after the nominated quit date. The primary outcome was self-reported point-prevalence (ie, not a single puff of a cigarette in the past seven days) at 24 weeks after the nominated quit date. At baseline and 24 weeks, self-reported physical activity levels were measured with the International Physical Activity Questionnaire - Long Form [8].

Health-related quality of life (HRQoL) was assessed using the EQ-5D questionnaire with utility values obtained from NZ tariff 2. Perfect health and death are anchored at utilities of 1 and 0 , respectively. 'Imperfect' health is valued at less than 1 . The time spent at a specific utility was used to generate a quality-adjusted life-year (QALY). For example, if one year with advanced stage lung cancer has a utility of 0.56 , then half a year with that disease is equivalent to 0.28 QALYs.

Table 2 details the key parameters used in the model. Gender-specific continuous abstinence rates and health-state utility values (for the 'well and smoking' states) have been taken from the trial data. Epidemiological data were sourced from NZ life tables, disease incidence rates, national databases and international literature.

Health-state utilities for cardiovascular disease (CVD) were taken from Sullivan et al. [9] where communitybased UK preferences were applied to EQ-5D descriptive questionnaire responses in the US-based Medical Expenditure Panel Survey $(n=79,522)$; coronary artery 
Table 1 Baseline characteristics for trial participants by group

\begin{tabular}{|c|c|c|c|}
\hline & $\begin{array}{l}\text { Control } \\
(n=455)\end{array}$ & $\begin{array}{l}\text { Intervention adherent } \\
(n=236)\end{array}$ & $\begin{array}{l}\text { Intervention non-adherent } \\
(n=219)\end{array}$ \\
\hline Age (years), mean $\pm S D$ & $37.3 \pm 12.2$ & $39.8 \pm 12.4$ & $35.2 \pm 11.7$ \\
\hline \multicolumn{4}{|l|}{ Sex, $n(\%)$} \\
\hline Male & $207(45.9)$ & $105(44.5)$ & $103(47)$ \\
\hline Female & $244(54.1)$ & $131(55.5)$ & $116(53)$ \\
\hline \multicolumn{4}{|l|}{ Prioritised ethnicity, n (\%) } \\
\hline NZ European & $214(47.5)$ & $132(55.9)$ & $86(39.3)$ \\
\hline Māori & 138 (30.6) & $63(26.7)$ & $79(36.1)$ \\
\hline Pacific & $55(12.2)$ & $15(6.4)$ & $32(14.6)$ \\
\hline Asian & $11(2.4)$ & $5(2.1)$ & $8(3.7)$ \\
\hline Other & $33(7.3)$ & $21(8.9)$ & $14(6.4)$ \\
\hline Number of cigarettes/day, mean \pm SD & $19.8 \pm 9.2$ & $20 \pm 10.5$ & $18.8 \pm 8.1$ \\
\hline Age of smoking onset (years), mean \pm SD & $15.5 \pm 4.2$ & $15.9 \pm 4.9$ & $15.1 \pm 3.3$ \\
\hline Years smoking continuously, mean \pm SD & $20.3 \pm 11.9$ & $21.7 \pm 12.4$ & $18.5 \pm 11.5$ \\
\hline Fagerström Test of Nicotine Dependence score, mean \pm SD & $5.6 \pm 2$ & $5.5 \pm 1.9$ & $5.5 \pm 1.9$ \\
\hline \multicolumn{4}{|l|}{ Previous quit attempts, $n(\%)$} \\
\hline Yes & $348(77.2)$ & $194(82.2)$ & $174(79.5)$ \\
\hline No & $103(22.8)$ & $42(17.8)$ & $45(20.6)$ \\
\hline \multicolumn{4}{|l|}{ Number of quit attempts in previous 12 months, $n(\%)$} \\
\hline Never attempted to quit before & $103(22.8)$ & $42(17.8)$ & $45(20.6)$ \\
\hline None & $204(45.2)$ & $113(47.9)$ & 89 (40.6) \\
\hline One & $83(18.4)$ & $43(18.2)$ & $50(22.8)$ \\
\hline Two & $28(6.2)$ & $19(8.1)$ & $18(8.2)$ \\
\hline Three & $14(3.1)$ & $11(4.7)$ & $4(1.8)$ \\
\hline Four or more & $18(4)$ & $8(3.4)$ & $12(5.5)$ \\
\hline Do not know & $1(0.2)$ & $0(0)$ & $1(0.5)$ \\
\hline \multicolumn{4}{|l|}{ Confidence to quit, $n$ (\%) } \\
\hline One (very low) & $8(1.8)$ & $2(0.9)$ & $5(2.3)$ \\
\hline Two & $15(3.3)$ & $5(2.1)$ & $7(3.2)$ \\
\hline Three & $97(21.5)$ & $30(12.7)$ & $53(24.2)$ \\
\hline Four & $140(31)$ & $76(32.2)$ & $72(32.9)$ \\
\hline Five (very high) & $190(42.1)$ & $123(52.1)$ & $81(37)$ \\
\hline Missing & $1(0.2)$ & $0(0)$ & $1(0.5)$ \\
\hline \multicolumn{4}{|l|}{ Physical activity (MET minutes/week), mean \pm SD } \\
\hline Leisure time domain & $601 \pm 1,150$ & $498 \pm 799$ & $621 \pm 1,343$ \\
\hline Work domain & $3,557 \pm 6,370$ & $3,982 \pm 6,532$ & $4,015 \pm 7,096$ \\
\hline Active transport domain & $437 \pm 1,047$ & $338 \pm 1,025$ & $531 \pm 1,720$ \\
\hline Domestic and garden domain & $1,838 \pm 2,877$ & $1,665 \pm 2,218$ & $1,930 \pm 3,032$ \\
\hline Total walking & $1,769 \pm 2,838$ & $1,844 \pm 2,706$ & $1,634 \pm 2,534$ \\
\hline Total moderate physical activity & $3,191 \pm 3,728$ & $3,030 \pm 3,460$ & $3,624 \pm 4,453$ \\
\hline Total vigorous physical activity & $1,472 \pm 3,728$ & $1,643 \pm 4,008$ & $1,832 \pm 4,316$ \\
\hline Total physical activity & $6,481 \pm 7,226$ & $6,489 \pm 7,389$ & $7,132 \pm 8,325$ \\
\hline
\end{tabular}


Table 2 Data parameters in model

\begin{tabular}{|c|c|c|c|c|}
\hline \multirow[t]{2}{*}{ Model parameter } & \multicolumn{2}{|l|}{ Mean (se) } & \multirow[t]{2}{*}{ Distribution } & \multirow[t]{2}{*}{ Source } \\
\hline & Male & Female & & \\
\hline \multicolumn{5}{|l|}{ Smoking } \\
\hline \multicolumn{5}{|l|}{ 24-week point prevalence rates } \\
\hline a) intervention - adherent group $(n=236)$ & $35.2 \%(4.7 \%)$ & $29.8 \%(4.0 \%)$ & Beta & Trial \\
\hline b) usual care & $24.2 \%(3.0 \%)$ & $19.7 \%(2.5 \%)$ & Beta & Trial \\
\hline Relapse rate from 24 weeks (end of trial) to 12 months & $21 \%$ & a & & [25] \\
\hline Relapse rates after 12 months & $30 \%$ cumulative & a & & [26] \\
\hline \multicolumn{5}{|l|}{ Lung cancer } \\
\hline Annual incidence & eg $0.00180^{b}$ & eg $0.00165^{b}$ & Beta & [27] \\
\hline Proportion - early stage lung cancer (I\&II) & $20 \%$ & a & & [14] \\
\hline Proportion - adv stage lung cancer (III\&IV) & $80 \%$ & a & & [14] \\
\hline \multirow[t]{2}{*}{ Relative risk of lung cancer in ex-smokers vs. general population } & eg 1.771 & a & & [14] \\
\hline & 15 years after quitting ${ }^{b}$ & & & \\
\hline \multicolumn{5}{|l|}{ CVD } \\
\hline Annual incidence & eg $0.03095^{b}$ & eg $0.01843^{b}$ & Beta & [28] \\
\hline Relative risk of CVD in smokers vs. general population & $1.42(0.031)$ & a & LogNormal & [29] \\
\hline Relative risk of CVD in ex-smokers vs. smokers & $0.71(0.036)$ & a & LogNormal & [29] \\
\hline \multicolumn{5}{|l|}{ Mortality } \\
\hline a) pre-hospital death given a CVD event & $18.1 \%$ & a & & [30] \\
\hline b) post-hospital death given a CVD event ( $\leq 28$ days) & $7.1 \%$ & a & & [30] \\
\hline c) background mortality (annual) & eg $0.01071^{b}$ & eg $0.00715^{b}$ & Beta & [31] \\
\hline \multicolumn{5}{|l|}{ Utility scores } \\
\hline \multicolumn{5}{|l|}{ a) well (no lung cancer or CVD) } \\
\hline baseline & 0.800 & a & & Trial \\
\hline continue smoking after end of trial & 0.800 & a & & Assumption \\
\hline abstain from smoking at end of trial & 0.830 & a & & [11] \\
\hline b) early stage lung cancer & $0.73(0.020)$ & a & Beta & [14] \\
\hline adv stage lung cancer & $0.56(0.043)$ & a & Beta & [9] \\
\hline c) weighted average CVD & 0.611 & & & {$[9,10]$} \\
\hline \multicolumn{5}{|l|}{ Excess health system costs (NZ\$) } \\
\hline a) lung cancer, first year of diagnosis & eg $23,970^{b}$ & eg $22,256^{\mathrm{b}}$ & Gamma & [13] \\
\hline lung cancer, subsequent annual costs before death & eg $5,375^{b}$ & eg $4,341^{b}$ & Gamma & [13] \\
\hline lung cancer, last six months before cancer death & eg $16,615^{b}$ & eg $20,300^{b}$ & Gamma & [13] \\
\hline b) $C V D$, first year of diagnosis if hospitalised & eg $11,327^{b}$ & eg $10,189^{b}$ & Gamma & [13] \\
\hline CVD, last six months before CVD death & eg $17,573^{b}$ & eg $11,048^{b}$ & Gamma & [13] \\
\hline
\end{tabular}

NZ\$1 = US\$0.68= = $€ .53$

${ }^{\text {a }}$ Same value for both sexes

${ }^{\mathrm{b}} \mathrm{Age/time-dependent} \mathrm{values} \mathrm{used} \mathrm{in} \mathrm{tables.} \mathrm{If} \mathrm{no} \mathrm{other} \mathrm{details} \mathrm{are} \mathrm{given,} \mathrm{then} \mathrm{the} \mathrm{example} \mathrm{is} \mathrm{for} \mathrm{a} 65$-year-old individual

disease (0.629), cerebrovascular disease and stroke (0.649), congestive heart failure (0.493), and peripheral vascular disease (0.657). Each disease state was then weighted by their proportional incidence in the National Minimum Dataset (NMDS) [10] of NZ CVD hospital admissions, respectively $54.9,21.9,17.6$, and $5.6 \%$, to give a composite CVD utility of 0.611 .
It was assumed that the utility after quitting smoking, and being CVD and lung cancer free, would improve by 0.03: Tillman and Silcock [11] noted this difference between smokers (0.75) and ex-smokers after 5 years abstinence $(0.78)$ using the EQ-5D $(n=1,623)$. Similarly, Xie et al. [12] reported a difference of 0.04 in EQ-5D utilities between those not smoking 0.88 and those 
smoking 0.84 in the Medical Expenditure Panel Survey data $(n=39,680)$.

\section{Cost data}

Costs gathered for the trial consisted of those from the GRx-related intervention and the programme set-up. The latter comprised the training costs for the intervention PSP, and PSP staff salary costs. The total training costs were amortised over all the participants in the intervention arm. Although referral to the GRx service was by researcher in the trial, the cost of GP referral is included. The cost per participant for Quitline was taken from their 2013 annual report.

Out-of-trial cost data by age, gender, and disease were estimated from the NZ HealthTracker database (Table 2). This database is a linkage system for all nationally collected health events, linked together by a personal unique identifier (National Health Index number). Each health event is linked to a unit resource cost, these include inpatient hospitalisations, outpatient attendance, laboratories, pharmaceuticals and (average capitation only from) general practice. Excess health system costs (healthcare costs above that for the healthy population) by age and gender, were calculated for the first year of diagnosis, subsequent annual costs (lung cancer only), and in the final six months of life for the disease states modelled [13].

Costs were reported in NZ\$, net of Goods and Sales Tax, at 2012 base prices; they were inflated to 2012 price levels, where necessary, using the Consumer Price Index. Purchasing power parity exchange rates were used to convert currencies. The economic analysis took a NZ health system perspective.

\section{Markov model}

The Markov model aimed to estimate the lifetime incremental costs and QALYs of adding the intervention to usual care. Trial costs and outcomes were used to parameterise this model.

In the base case, separate male and female cohorts were tracked from the age of 40 (the approximate average age of trial participants) until age 100. Two strategies were modeled; individuals either participated in usual care alone (Quitline) or the Fit2Quit intervention in addition to usual care.

Cohorts, starting in the 'well' state (Fig. 1), faced different probabilities of quitting smoking taken from the trial; relapse rates were included after continued abstinence at 24-week follow-up to 12 months, and in the three years beyond a successful quit attempt. The risk of developing lung cancer or CVD varied. Tunnel features have been built into the model for the lung cancer states to ensure that the risk of cancer progression or death is dependent upon the duration since diagnosis. For CVD, an assumption was made that an individual can have increased excess health system costs only in the year of diagnosis and death but they will have a permanently reduced HRQoL once they enter the CVD health state.

The Markov model is an extension of the smoking cessation model presented in Gordon et al. [14]. A CVD health state, NZ-specific epidemiological and cost data, different EQ-5D utility values and relapse pattern have been added. Readers are directed there for a more detailed explanation of the lung cancer component of the model, the structure of which remains unchanged.

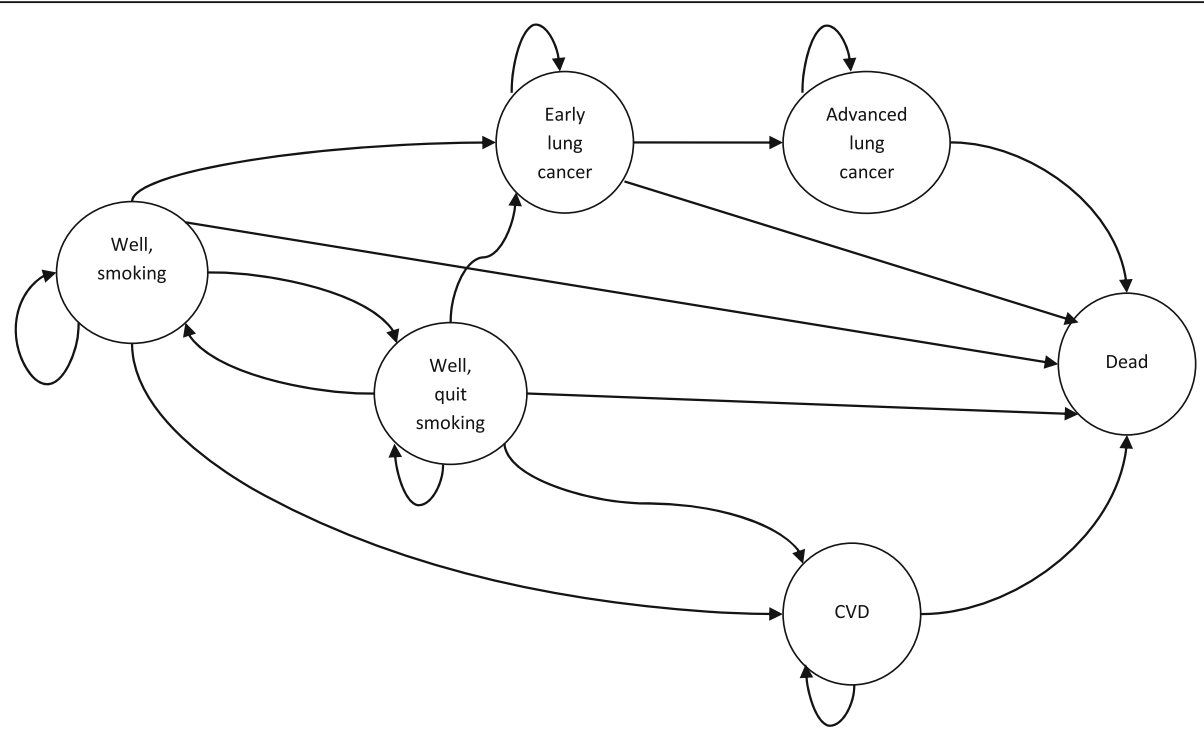

Fig. 1 State transition diagram 


\section{Analysis}

The within-trial analysis was on an intention-to-treat basis. In the Markov model, only analyses comparing the adherent intervention group (defined as having $70 \%$ of calls delivered [7]) vs. the usual care group were performed. All participants with missing smoking status were considered to be smokers.

All future costs and health outcomes have been discounted at $3.5 \%$ per annum. In scenario analyses, the following were tested: a 0 and $5 \%$ discount rate for both future costs and QALYs; and changing the initial age of the cohort to 30, 50 and 60-years old.

The effects of variations to the parameters with plausible uncertainty in the base case were assessed using one-way sensitivity analyses $( \pm 2$ standard deviations or $20 \%$ either way of the mean estimate), and simultaneously using probabilistic sensitivity analyses with Monte Carlo simulation and 1000 repetitions. Beta, log-normal, and gamma distributions were used for probabilities, relative risks, and costs, respectively (Table 2).

Incremental cost-effectiveness ratios (ICERs) were calculated to summarise the additional cost per unit of health benefit gained by switching from usual care to the intervention. For the trial analysis, the ICERs only included the programme costs, as additional costs to the health sector over those 24 weeks were not collected. All analyses were conducted using TreeAge Pro 2014 and Stata SE v11. Statistical tests were two-tailed and a 5\% significance level was used. The Consolidated Health Economic Evaluation Reporting Standards (CHEERS) was adhered to [15].

\section{Results}

\section{Within-trial cost-effectiveness}

Descriptive data of the quit rates, HRQoL, leisure-time physical activity outcome measures and trial costs used for the cost-effectiveness analysis are presented in Table 3. Leisure-time physical activity showed a significant between-group change from baseline of 219 MET mins per week (adjusted difference) in favour of the intervention $(p=0.01)$. The average total cost per participant for the intervention group was NZ\$ 623 and in the control arm was NZ\$ 195.

Over the 24-week follow-up, after adjustment for baseline HRQoL, there was a non-significant gain of 0.001 QALYs (95\% CI: -0.006 to 0.008 ) in favour of the intervention, giving an ICER of NZ\$ 451,000 per QALY gained. The ICER for 7-day point prevalence measured

Table 3 Trial outcomes and costs

\begin{tabular}{|c|c|c|c|c|}
\hline \multirow[t]{2}{*}{ Outcomes } & Intervention $(n=455)$ & Usual care $(n=451)$ & \multicolumn{2}{|l|}{ Difference } \\
\hline & Mean (se) & Mean (se) & \multicolumn{2}{|c|}{ Mean $(95 \% \mathrm{Cl})$} \\
\hline \multicolumn{5}{|l|}{ Quit rates at 24-week follow-up } \\
\hline Point prevalence & $23.1 \%(2.0 \%)$ & $21.7 \%(1.9 \%)$ & \multicolumn{2}{|c|}{$1.3 \%(-4.1$ to $6.8 \%)$} \\
\hline \multicolumn{5}{|l|}{ EQ-5D utility scores } \\
\hline Baseline & $0.792(0.01)$ & $0.800(0.01)$ & \multicolumn{2}{|c|}{$-0.008(-0.035$ to 0.019$)$} \\
\hline 24-week follow-up & $0.800(0.01)$ & $0.803(0.01)$ & \multicolumn{2}{|c|}{$-0.002(-0.029$ to 0.025$)$} \\
\hline \multicolumn{5}{|l|}{ Leisure-time physical activity (MET mins/week) } \\
\hline Change from baseline & $526(69)$ & $307(66)$ & \multicolumn{2}{|c|}{219 (53 to 386) } \\
\hline Costs & Quantity & Unit cost & 2012 NZ\$ & Source \\
\hline \multicolumn{5}{|l|}{ Intervention, programme costs } \\
\hline a) training for PSPs provided by investigators (trainer hours) & 9 & 125 & 1,125 & Trial \\
\hline b) PSP salary incl. $25 \%$ overhead & 2 & 75,000 & 150,000 & Trial \\
\hline \multicolumn{5}{|l|}{ Intervention, cost per participant $(n=455)$} \\
\hline a) PSP training costs per Fit2Quit participant & & & 2.47 & Trial \\
\hline b) PSP salary & & & 329.67 & Trial \\
\hline c) GP visit for Green Prescription & & & 65.00 & Estimate \\
\hline d) pedometer & 1 & 30.44 & 30.44 & Trial \\
\hline \multirow[t]{2}{*}{ e) Quitline } & 1 & 195.33 & 195.33 & {$[32]$} \\
\hline & & Total & 622.91 & \\
\hline Usual care, Quitline cost per participant $(n=451)$ & & Total & 195.33 & [32] \\
\hline
\end{tabular}


at 24-week follow-up was NZ\$ 31,733 per smoker abstaining. Both values are unlikely to be considered cost-effective.

For the 52\% who adhered to the intervention, the ICER for 7-day point prevalence measured at 24-week follow-up was NZ\$3,991 per smoker abstaining - with $32.2 \%$ (se $=3.0 \%$ ) abstaining in the adherent group.

\section{Lifetime cost-effectiveness for the adherent intervention group}

In the Monte Carlo simulations, for a cohort with a starting age of 40 years, the adherent intervention participants compared with the control group gained 0.057 (males) and 0.068 (females) discounted QALYs till age 100 (Table 4). The ICERs were NZ\$ 4,431 and NZ\$ 2,909 per QALY gained for males and females respectively. At a threshold of NZ\$20,000 per QALY gained, there was an $86 \%$ (males) and $90 \%$ (females) probability that the Fit2Quit intervention is cost-effective. In oneway sensitivity analyses of the base case, the main driver of uncertainty was the 12-month quit rates with other variables only having a minor impact.

In scenario analyses, when varying the initial age of the cohort, discounted incremental QALYs were marginally higher, discounted incremental costs were lower and thus ICERs were more favourable for older cohorts. The probability that the intervention was cost-effective at NZ\$ 20,000 per QALY gained ranged from 78 to $90 \%$ in these analyses.

\section{Discussion}

To our knowledge, this is the first published costeffectiveness analysis of an exercise-counselling intervention for smoking cessation. Positive effects were observed for those who adhered to the intervention, and for this subgroup it is likely to be cost-effective compared to usual care for increasing quit rates.

This study has several strengths; baseline prognostic factors were well-balanced, it is the largest study of its kind and the intervention was conservatively costed. For example, the intervention included an expensive NZ\$ 30 Yamax SW-700 pedometer, which may not be necessary in practice as pedometer apps are now widely available for smartphones. The cost of GP referral was also included, although this was not necessary in the trial.

The study aimed to leverage existing national delivery services for both smoking cessation and physical activity promotion. The intervention was effective for increasing leisure-time physical activity. Physical activity is beneficial for a wide range of other health risks and outcomes such as depression, Type 2 diabetes, CVD and various cancers [16]. Therefore it is important that physically inactive or insufficiently active people who smoke are referred to programs to increase activity levels.

If the intervention could be targeted at those who would be willing to commit to seven or more intervention calls (the adherent group), the intervention may be more effective and probably cost-effective over 24 weeks compared to Quitline alone. Further, over the lifetime of the 40-year-old cohort (who were adherent to the intervention), Markov modelling suggests that the intervention may be cost-effective in improving HRQoL. These findings highlight the need to identify smokers who want to quit and screen for readiness to exercise to truly realise the benefits of such an approach and maximize smoking cessation outcomes: issues identified earlier [17].

There are limitations to this economic evaluation. First, verification of quit status was not undertaken due

Table 4 Lifetime cost-effectiveness for the adherent group

\begin{tabular}{|c|c|c|c|c|c|c|c|c|}
\hline Adherent group & 40-year-old male & & & & 40-year-old fem & & & \\
\hline Base case & Intervention & Usual care & Difference & & Intervention & Usual care & Difference & \\
\hline Mean cost per person (NZ\$) & 9,952 & 9,700 & 253 & & 11,032 & 10,833 & 199 & \\
\hline QALYs gained per person & 16.680 & 16.623 & 0.057 & & 17.398 & 17.330 & 0.068 & \\
\hline ICER per QALY (NZ\$) & & & 4,431 & & & & 2,909 & \\
\hline Probability cost effective ${ }^{a}$ & & & 0.860 & & & & 0.902 & \\
\hline Scenarios & Incr. costs (NZ\$) & Incr. QALYS & ICER (NZ\$) & $\begin{array}{l}\text { Probability } \\
\text { cost effective }^{a}\end{array}$ & Incr. costs (NZ\$) & Incr. QALYS & ICER (NZ\$) & $\begin{array}{l}\text { Probability } \\
\text { cost effective }\end{array}$ \\
\hline $0 \%$ discount rate for costs \& QALYs & -68 & 0.158 & Dominant & 0.894 & -220 & 0.186 & Dominant & 0.893 \\
\hline $5 \%$ discount rate for costs \& QALYs & 310 & 0.042 & 7,404 & 0.831 & 272 & 0.051 & 5,371 & 0.886 \\
\hline 30-year-old cohort & 307 & 0.055 & 5,633 & 0.879 & 275 & 0.061 & 4,521 & 0.895 \\
\hline 50-year-old cohort & 189 & 0.064 & 2,942 & 0.858 & 238 & 0.070 & 3,419 & 0.847 \\
\hline 60-year-old cohort & 128 & 0.065 & 1,976 & 0.777 & 203 & 0.069 & 2,962 & 0.814 \\
\hline
\end{tabular}

at NZ\$ $20 \mathrm{k}$ per QALY. NZ\$1 $=$ US\$0.68 $=€ 0.53$

ICER incremental cost-effectiveness ratio, $Q A L Y$ quality-adjusted life-year 
to the use of telephone-based assessments. Previous reviews of smoking cessation studies have shown that rates of misreporting of smoking abstinence are generally less than 5\% [18]. Second, using the Markov model, the CVD and lung cancer states were mutually exclusive, and other (non-lung) cancers and respiratory diseases were not modeled. This may underestimate the impact of the intervention on future health outcomes and healthcare costs averted. Our reported QALY gains are below the benchmarks published by Stapleton and West [19]. While the costs of those other co-morbidities have not been modeled, their disutility may have been captured by the use of unadjusted population-based CVD and lung cancer utility scores. Third, the Markov model risk parameters for lung cancer were originally specified for heavy smokers ( $\geq 20$ cigarettes/day) and may not apply to light smokers or those without the requisite pack-years. Fourth, and finally this economic evaluation using a lifetime horizon is limited to the adherent intervention subgroup: blanket provision for all smokers contacting Quitline is unlikely to be cost-effective. As this adherent subgroup was not prospectively defined, these results should be interpreted with caution and viewed as hypothesis generating. However, we wanted to explore what would make the intervention more cost-effective - higher quitting through greater adherence was a possibility.

Further research should be focused on identifying those who might be willing to commit to seven or more intervention calls. Improvements to the Fit2Quit intervention could include greater tailoring of the call schedule, increased face-to-face contact, and the provision of a support group. In addition, supplementing with electronic support, eg text messaging [20] or a smoking cessation smartphone app [21], is highly likely to improve cost-effectiveness [22]. Other options could include a commitment contract [23], or funding/ provision through the workplace [24] and/or health insurance, where the productivity gains (not estimated here) and reduced claims may provide an incentive to intervene.

\section{Conclusion}

If the exercise-counselling intervention could be targeted at those who would be willing to commit to seven or more intervention calls, it may be cost-effective compared to Quitline alone - improving both abstinence and leisure-time physical activity. Screening for readiness to exercise, an omission in the trial, would likely have helped to identify those potentially adherent.

\section{Abbreviations}

CVD: Cardiovascular disease; EQ-5D: EuroQol five dimensions questionnaire; GRx: Green prescription; HRQoL: Health-related quality of life;

ICER: Incremental cost-effectiveness ratio; MET: Metabolic equivalent of task;
NZ: New Zealand; PPP: Purchasing power parity; PSP: Participant-support person; QALY: Quality-adjusted life-year

\section{Acknowledgements}

We thank the participants, Quitline and exercise-counselling support staff in our study. We are grateful to Tiffany Hung (University of Cardiff, now JPMorgan Chase \& Co.) for assistance with data management and analysis.

\section{Funding}

This was an investigator-initiated study funded by a grant from the Health Research Council of New Zealand (09/338R) and a small project grant from the Heart Foundation of New Zealand (1405). RM was supported by a Heart Foundation of New Zealand Fellowship. VR was supported by a University of Auckland Doctoral Scholarship. The funders played no role in the design, conduct or analysis of the study, nor in the interpretation and reporting of the study findings. The researchers were independent from the funders.

\section{Availability of data and materials}

All data generated or analysed during this study are included in these published articles [and their supplementary information files]: (a) Maddison R et al. Exercise Counseling to Enhance Smoking Cessation Outcomes: The Fit2Quit Randomized Controlled Trial. Annals of Behavioral Medicine 2014, 48(2):194-204; and (b) Gordon L et al. Within a smoking-cessation program, what impact does genetic information on lung cancer need to have to demonstrate cost-effectiveness? Cost Effectiveness \& Resource Allocation 2010, 8:18.

\section{Authors' contributions}

Design and conception of the study: WL, RM. Analysis of data: WL, YJ. Interpretation of data: $W L, L G$. Drafting and revision of the manuscript: $W L$, RM, LG, VR, CB, HP. Acquisition of data: WL, RM, LG, YJ, VR, CB. Final approval of the manuscript: $W L, R M, L G, C B, Y J, H P, H M$, VR.

\section{Competing interests}

William Leung, Ralph Maddison, Vaughan Roberts, Louisa Gordon, Harry Prapavessis, and Yannan Jiang declare that they have no conflict of interest. Christopher Bullen has received support for accommodation while a speaker hosted by a manufacturer of smoking cessation drugs but has no other interests to declare. Hayden McRobbie has received honoraria for speaking at research symposia and received benefits in kind and travel support from and has provided consultancy to the manufacturers of smoking-cessation medications, specifically Pfizer, GSK, and J\&J.

Consent for publication

Not applicable.

\section{Ethics approval and consent to participate}

The authors assert that all procedures contributing to this work comply with the ethical standards of the relevant national and institutional committees on human experimentation and with the Helsinki Declaration of 1975, as revised in 2008. Study procedures and terms were approved by the New Zealand Multi-region Ethics Committee (MEC/09/08/090).

\section{Publisher's Note}

Springer Nature remains neutral with regard to jurisdictional claims in published maps and institutional affiliations.

\footnotetext{
Author details

${ }^{1}$ University of Otago, WellingtonPO Box $7343 \mathrm{New}$ Zealand. ${ }^{2}$ University of Auckland, Private Bag 92019, Auckland, New Zealand. ${ }^{3}$ Berghofer Medical Research Institute, Brisbane, Australia. ${ }^{4}$ UK Centre for Tobacco Control Studies, Wolfson Institute of Preventive Medicine, Barts \& The London School of Medicine and Dentistry, Queen Mary University of London, London, UK. ${ }^{5}$ School of Kinesiology, Faculty of Medical and Health Sciences, University of Western Ontario, 1151 Richmond St, London, ON, Canada. ${ }^{6}$ Centre for Physical Activity and Nutrition, Deakin University, Melbourne, VIC, Australia.
} 
Received: 22 November 2016 Accepted: 20 March 2017 Published online: 29 March 2017

\section{References}

1. Ng M, Freeman MK, Fleming TD, Robinson M, Dwyer-Lindgren $L$, Thomson B, Wollum A, Sanman E, Wulf S, Lopez AD. Smoking prevalence and cigarette consumption in 187 countries, 1980-2012. JAMA. 2014;311(2):18392.

2. Braillon A. Curbing the tobacco epidemic: employing behavioral strategies or rearranging the deckchairs on the Titanic? Prev Med. 2015;73:28-9.

3. Ussher $\mathrm{MH}$, Taylor $\mathrm{AH}$, Faulkner $\mathrm{G}$. Exercise interventions for smoking cessation. Cochrane Database Syst Rev. 2014;8:CD002295. doi:10.1002/ 14651858.CD002295.pub5.

4. Maddison R, Roberts V, Bullen C, McRobbie H, Jiang Y, Prapavessis H, Glover M, Taylor S, Brown P. Design and conduct of a pragmatic randomized controlled trial to enhance smoking-cessation outcomes with exercise: the Fit2Quit study. Ment Health and Phys Act. 2010;3(2):92-101.

5. Swinburn B, Walter $L$, Arroll B, Tilyard M, Russell D. The green prescription study: a randomized controlled trial of written exercise advice provided by general practitioners. Am J Public Health. 1998;88(2):288-91.

6. US Department of Health \& Human Services. Physical activity and health: a report of the Surgeon General. Atlanta: U.S. Department of Health \& Human Services, Centers for Disease Control and Prevention, National Center for Chronic Disease Prevention and Health Promotion; 1996. p. 137.

7. Maddison R, Roberts V, McRobbie H, Bullen C, Prapavessis H, Glover M, Jiang Y, Brown P, Leung W, Taylor S, et al. Exercise counseling to enhance smoking cessation outcomes: the Fit2Quit randomized controlled trial. Ann Behav Med. 2014;48(2):194-204.

8. Craig $C L$, Marshall AL, Sjorstrom M, Bauman AE, Booth ML, Ainsworth BE, Pratt M, Ekelund U, Yngve A, Sallis JF. International physical activity questionnaire: 12-country reliability and validity. Med Sci Sports Exerc. 2003;35(8):1381-95.

9. Sullivan P, Slejko J, Sculpher M, Ghushchyan V. Catalogue of EQ-5D scores for the United Kingdom. Med Decis Mak. 2011;31(6):800-4.

10. NZ Health Information Service. In: NZHIS, editor. National Minimum Dataset. 2006 to 2007. Wellington: New Zealand Health Information Service; 2007.

11. Tillmann M, Silcock J. A comparison of smokers' and ex-smokers' healthrelated quality of life. J Public Health Med. 1997;19(3):268-73.

12. Xie J, Wu E, Zheng Z, Croft J, Greenlund K, Mensah G, et al. Impact of stroke on health-related quality of life in the noninstitutionalized population in the United States. Stroke. 2006;37(10):2567-72.

13. Health System Costs of Tobacco-Related Diseases [ http://www.otago.ac.nz/ wellington/departments/publichealth/research/bode3/otago075379.html ]. Accessed 23 Feb 2016

14. Gordon L, Hirst N, Young R, Brown P. Within a smoking-cessation program, what impact does genetic information on lung cancer need to have to demonstrate cost-effectiveness?. Cost Effectiveness \& Resource Allocation. 2010;8:18.

15. Husereau D, Drummond M, Petrou S, Carswell C, Moher D, Greenberg D, Augustovski F, Briggs AH, Mauskopf J, Loder E. Consolidated health economic evaluation reporting standards (CHEERS) — explanation and elaboration: a report of the ISPOR health economic evaluation publication guidelines good reporting practices task force. Value Health. 2013;16(2):231-50.

16. Moore SC, Lee I-M, Weiderpass E, Campbell PT, Sampson JN, Kitahara CM, Keadle SK, Arem H, de Gonzalez AB, Hartge P. Association of leisure-time physical activity with risk of 26 types of cancer in 1.44 million adults. JAMA Intern Med. 2016;176(6):816-25.

17. Roberts V, Dale LP, Dorey E, Bullen C, Maddison R. An exercise programme for smoking cessation: perceptions of the Fit2quit trial intervention. J Smok Cessat. 2014; FirstView:1-8.

18. Velicer WF, Prochaska JO, Rossi JS, Snow MG. Assessing outcome in smoking cessation studies. Psychol Bull. 1992;111(1):23.

19. Stapleton J, West R. A direct method and ICER tables for the estimation of the cost-effectiveness of smoking cessation interventions in general populations: application to a new cytisine trial and other examples. Nicotine Tob Res. 2012;14(4):463-71

20. Guerriero C, Cairns J, Roberts I, Rodgers A, Whittaker R, Free C. The costeffectiveness of smoking cessation support delivered by mobile phone text messaging: Txt2stop. Eur J Health Econ. 2013;14(5):789-97.

21. Hassandra M, Lintunen $T$, Kettunen $T$, Vanhala M, Toivonen H-M, Kinnunen K, Heikkinen R. Effectiveness of a mobile phone app for adults that uses physical activity as a tool to manage cigarette craving after smoking cessation: a study protocol for a randomized controlled trial. JMIR Res Protoc. 2015;4(4):e125

22. Whittaker $\mathrm{R}$, McRobbie $\mathrm{H}$, Bullen C, Borland R, Rodgers A, Gu Y. Mobile phone-based interventions for smoking cessation. Cochrane Database Syst Rev. 2012;11:CD006611. doi:10.1002/14651858.CD006611.pub3.

23. Cahill K, Hartmann-Boyce J, Perera R. Incentives for smoking cessation. Cochrane Database Syst Rev. 2015;5:CD004307. doi:10.1002/14651858. CD004307.pub5.

24. Cahill K, Lancaster T. Workplace interventions for smoking cessation. Cochrane Database Syst Rev. 2014;2:CD003440. doi:10.1002/14651858. CD003440.pub4

25. Stapleton J. Cigarette smoking prevalence, cessation and relapse. Stat Methods Med Res. 1998;7:187-203.

26. Etter J-F, Stapleton J. Nicotine replacement therapy for long-term smoking cessation: a meta-analysis. Tob Control. 2006;15:280-5.

27. Ministry of Health. Selected cancers 2012, 2013 \& 2014 (provisional). Wellington: Ministry of Health; 2015.

28. Grey C, Wells S, Riddell T, Kerr A, Gentles D, Pylypchuk R. A comparative analysis of the cardiovascular disease risk factor profiles of Pacific peoples and Europeans living in New Zealand assessed in routine primary care: PREDICT CVD-11. N Z Med J. 2010;123(1309):62-75.

29. Asia Pacific Cohort Studies Collaboration. Smoking, quitting, and the risk of cardiovascular disease among women and men in the Asia-Pacific region. Int J Epidemiol. 2005;34:1036-45.

30. Marshall R, Milne R, Lynn R, Jackson R. Quantifying the effect of age on short-term and long-term case fatality in 14,000 patients with incident cases of cardiovascular disease. Eur J Cardiovasc Prev Rehabil. 2008;15(2):179-84.

31. Statistics New Zealand. New Zealand period life tables: 2012-14. Wellington: Statistics New Zealand; 2015.

32. Quitline. Quitline me mutu annual review 2012/2013. Wellington: Quitline; 2013

\section{Submit your next manuscript to BioMed Central and we will help you at every step:}

- We accept pre-submission inquiries

- Our selector tool helps you to find the most relevant journal

- We provide round the clock customer support

- Convenient online submission

- Thorough peer review

- Inclusion in PubMed and all major indexing services

- Maximum visibility for your research

Submit your manuscript at www.biomedcentral.com/submit
) Biomed Central 